\title{
Malassezia pachydermatis (Weidman) C.W. Dodge
}

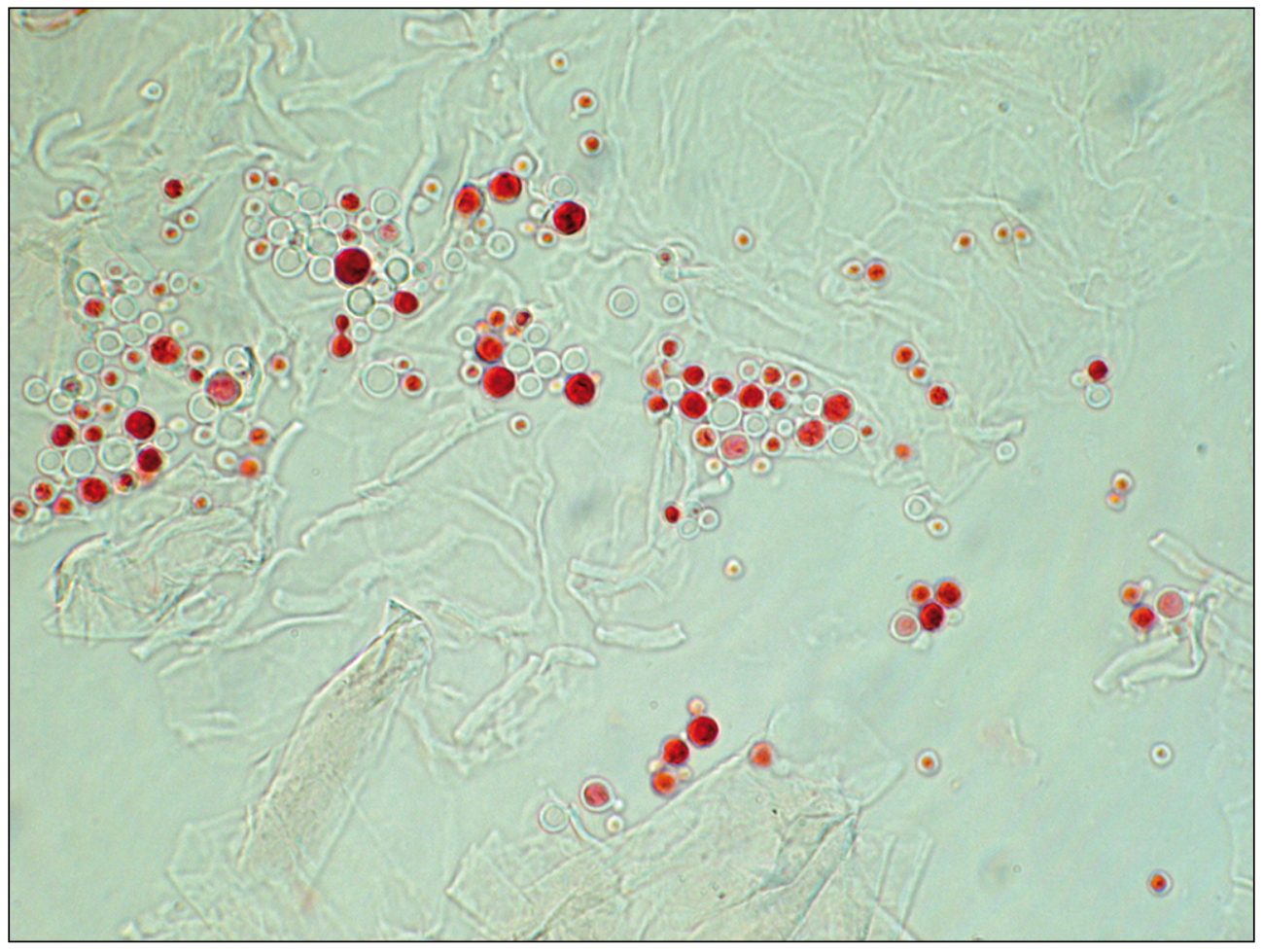

Figura 1. Levaduras globosas en grupos de un paciente con pitiriais versicolor dorsal. Examen de cinta adhesiva teñida con safranina al $0,5 \%$.

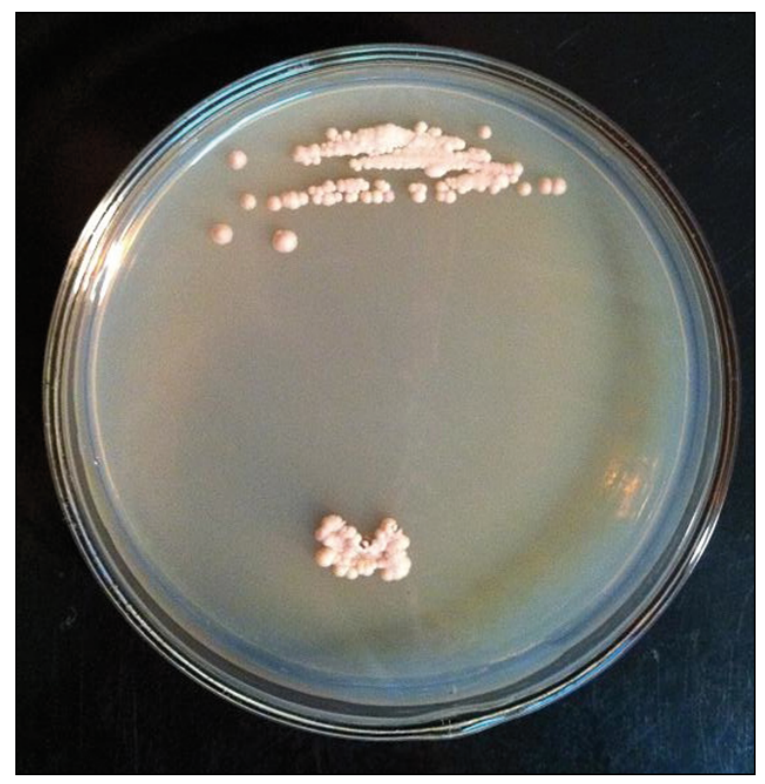

Figura 2. Colonia de $M$. pachydermatis en CHROMagar Malassezia a $32^{\circ} \mathrm{C}$ por 10 días. 


\section{Malassezia pachydermatis (Weidman) C.W. Dodge}

Las especies del género Malassezia son un grupo de levaduras lipofílicas que forman parte de la micobiota de la piel, tanto del ser humano como de animales. En la actualidad, en base a morfofisiología y biología molecular se han identificado 14 especies, siendo Malassezia pachydermatis la única no lipodependiente, por lo que crece en medios comunes como el agar Sabouraud. Esta especie fue aislada por primera vez en 1925 por Weidman. Es considerada una levadura zoofílica porque está presente en la piel y conducto auditivo externo de animales silvestres y domésticos, pudiendo provocar en éstos dermatitis y otitis. En humanos se aísla ocasionalmente en pitiriasis versicolor, dermatitis seborreica y en fungemias asociadas a catéter venoso central en neonatos. En Chile, se ha identificado como agente de pitiriasis versicolor principalmente en pacientes con infección por VIH.

Examen microscópico directo de lesiones de piel: Se puede realizar con cinta adhesiva y tinción con safranina al $0,5 \%$. También puede obtenerse una muestra por raspado superficial y aplicar $\mathrm{KOH}$ al $40 \%$, azul de metileno o blanco de calcofluor. Se observan levaduras globosas a elipsoides, generalmente en grupos, con o sin micelio grueso de corta longitud (Figura 1).

Cultivo: Las muestras obtenidas por raspado de piel deben ser sembradas en agar Sabouraud, y para el aislamiento de otras especies en medio Dixon o Leeming y Notman por 10 días a $32^{\circ} \mathrm{C}$. El agar Sabouraud con aceite de oliva es útil, sin embargo, tiene menor sensibilidad que los otros medios. El cultivo en CHROMagar Malassezia a $32^{\circ} \mathrm{C}$ por 10 días permite, por el color de las colonias, diferenciar algunas especies del género. Malassezia pachydermatis produce colonias lisas de color rosado pálido (Figura 2).

Prueba de asimilación de Tween: A colonias homogeneizadas en agar Sabouraud estéril fundido y luego solidificado se les realiza cuatro orificios rellenados con gotas de Tween 20, 40, 60 y 80; respectivamente. Las placas son incubadas a $32^{\circ} \mathrm{C}$ por 10 días. Malassezia pachydermatis asimila los Tween 40,60 y 80.

Identificación molecular: La morfofisiología puede no ser suficiente en la identificación de algunas cepas lipodependientes, por lo que la secuenciación de algunos genes (por ejemplo, ITS-5.8S y 26S rRNA D1D2, $\beta$-tubulina) o el uso de nuevas herramientas como MALDI-TOF pueden ser necesarias.

Rodrigo Cruz y Peggy Vieille Cátedra de Micología, Universidad de Valparaíso

Versión in extenso disponible en www.sochinf.cl

Correspondencia a:

Rodrigo Cruz Ch.

rcruzchoappa@gmail.com 